This is the final peer-reviewed accepted manuscript of:

Sara De Berardis, Eleonora Laura De Paola, Giuseppe Montevecchi, Davide Garbini, Francesca Masino, Andrea Antonelli, Dora Melucci

Determination of four Alternaria alternata mycotoxins by QuEChERS approach coupled with liquid chromatography-tandem mass spectrometry in tomato-based and fruit-based products

Food Research International, 106 (2018) 677-685

The final published version is available online at:

DOI: 10.1016/j.foodres.2018.01.032

Rights / License:

The terms and conditions for the reuse of this version of the manuscript are specified in the publishing policy. For all terms of use and more information see the publisher's website: https://www.elsevier.com/solutions/sciencedirect/librarian-resource-center/rights-andpermissions

This item was downloaded from IRIS Università di Bologna (https://cris.unibo.it/)

When citing, please refer to the published version. 


\title{
Determination of four Alternaria alternata mycotoxins by QuEChERS approach coupled with liquid chromatography-tandem mass spectrometry in tomato-based and fruit-based products
}

\author{
Sara De Berardis ${ }^{\mathrm{a}, 1}$, Eleonora Laura De Paola ${ }^{\mathrm{b}}$, Giuseppe Montevecchi ${ }^{\mathrm{c}, *}$, Davide Garbini ${ }^{\mathrm{d}}$, \\ Francesca Masino ${ }^{\mathrm{b}, \mathrm{c}}$, Andrea Antonelli ${ }^{\mathrm{b}, \mathrm{c}}$, Dora Melucci ${ }^{\mathrm{a}}$ \\ a Department of Chemistry "Giacomo Ciamician", University of Bologna, Via Selmi 2, 40126 Bologna, Italy \\ ${ }^{\mathbf{b}}$ Department of Life Science (Agro-Food Science Area), University of Modena and Reggio Emilia, Via G. Amendola 2 (Padiglione Besta), 42122 Reggio Emilia, Italy \\ ${ }^{c}$ BIOGEST - SITEIA Interdepartmental Centre, University of Modena and Reggio Emilia, Piazzale Europa 1, 42124 Reggio Emilia, Italy \\ ${ }^{\mathrm{d}}$ Coop Italia soc.coop., Via del Lavoro 6/8, 40033, Casalecchio di Reno, Bologna, Italy
}

\section{A R T I C L E I N F O}

\section{Keywords:}

Alternaria alternata

Mycotoxins

Food contaminants

Tomato

QuEChERS

LC-ESI-MS/MS

\begin{abstract}
A B S T R A C T
A liquid chromatography-tandem mass spectrometry method for the determination of four Alternaria toxins, i.e. alternariol, alternariol monomethyl ether, tentoxin, and tenuazonic acid in tomato-based and fruit-based products was developed using a QuEChERs approach for the extraction of the mycotoxins. To optimise the QuEChERs extraction, several parameters were tested: types of QuEChERs pouches, sample weights, quantities of added water, use of dispersive SPE as a purification step, types of solvent and conditions of shaking. The method showed good linearity $\left(\mathrm{R}^{2}>0.997\right)$ and precision $(\mathrm{RSD} \%<10)$ for all analytes. Tenuazonic acid showed very good recovery $(98.8 \%-108.9 \%)$ for tomato-based products, as well as for fruit-based products. The method was successfully applied to 57 samples collected from the Italian market. Tenuazonic acid was found in appreciable concentrations in some products. The highest value was found in a tomato sauce sample $(814 \mu \mathrm{g} / \mathrm{kg})$.
\end{abstract}

\section{Introduction}

Alternaria microfungi are ubiquitous pathogens and saprophytes, capable of growing even at low temperatures. They were found in vegetables, cereals, fruits, and oilseeds (Tölgyesi, Stroka, Tamosiunas, \& Zwickel, 2015). Alternaria spp., and mainly Alternaria alternata, produce more than seventy secondary metabolites. Some of them were chemically characterised and known to act as mycotoxins to humans and animals (Bottalico \& Logrieco, 1992; Barkai-Golan, 2008; EFSA CONTAM Panel, 2011).

In 2011, in light of the concerns for human and animal health, the
European Food Safety Authority (EFSA) performed a risk assessment of some of the main Alternaria toxins, i.e. alternariol (AOH), alternariol monomethyl ether (AME), tentoxin (TEN), and tenuazonic acid (TeA). The conclusions were that $\mathrm{AOH}$ and AME were genotoxic in bacteria and mammalian cells in vitro (EFSA CONTAM Panel, 2011). As regards in vivo systems, only limited information was available and indications of precancerous changes were reported in oesophageal mucosa of mice (EFSA CONTAM Panel, 2011).

In 2016, EFSA collected occurrence data for AOH, AME, TEN, and TeA to estimate chronic dietary exposure to these mycotoxins (EFSA, Arcella, Eskola, \& Gómez Ruiz, 2016). AOH was found in grains and

\footnotetext{
Abbreviations: ACN, acetonitrile; AME, alternariol monomethyl ether; $\mathrm{AOH}$, alternariol; APCI, atmospheric pressure chemical ionisation; CAD, collision activated dissociation; CE, collision energy; CEP, collision cell entrance potential; CUR, curtain gas; CXP, collision cell exit potential; DON, deoxynivalenol; DP, declustering potential; d-SPE, dispersive solid phase extraction; EP, entrance potential; ESI, electrospray ionisation; FIA, flow injection mode; GC, gas chromatography; GS1, nebulizer gas; GS2, heater gas; HPLC, high performance liquid chromatography; i.d., Internal diameter; ISV, ion spray voltage; LC, liquid chromatography; LLOQ, lower limit of quantification; LOD, limit of detection; MS, mass spectrometry; MS/MS, tandem mass spectrometry; MW, Molecular weight; NIV, nivalenol; p.s., Particle size; PSA, primary secondary amine; QuEChERS, Quick easy cheap effective robust (or rugged) and safe; $\mathrm{R}^{2}$, Coefficient of determination; RP, Reversed phase; RSD, relative standard deviation; SD, standard deviation; SPME, Solid phase microextraction; S/N, Signal to noise ratio; SRM, selected reaction monitoring; TeA, tenuazonic acid; TEM, ESI temperature; TEN, tentoxin; TMS, Trimethylsilyl group; TP, sample of tomato pulp that showed concentrations < LOD for all the analytes and was used for the optimisation and evaluation of the method

* Corresponding author.

E-mail address: giuseppe.montevecchi@unimore.it (G. Montevecchi).

1 Present address: European Food Safety Authority (EFSA), Via Carlo Magno 1A, 43126 Parma, Italy.

Although one of the authors is currently employed with the European Food Safety Authority (EFSA), the present article is the result of activities held before the employment with EFSA, while affiliated with University of Bologna. It is published under the sole responsibility of the authors and shall not be considered as an EFSA scientific output.
} 
Table 1

List of the samples selected for the study and their characteristics (i.e. subgroup assigned on the basis of the composition of the product, if organic or baby food, consistency, country of origin and remaining shelf-life in months at the date of purchase).

\begin{tabular}{|c|c|c|c|c|c|c|}
\hline Sample number & Product & Subgroup & Organic/baby food & Consistency & Country of origin & $\begin{array}{l}\text { Remaining shelf-life at purchase } \\
\text { (months) }\end{array}$ \\
\hline 1 & Whole peeled tomatoes in tomato juice & $\mathrm{T}$ & & Solid/liquid & IT & 25 \\
\hline 2 & Tomato pulp & $\mathrm{T}$ & & Solid/liquid & IT & 13 \\
\hline 3 & Tomato sauce & $\mathrm{T}$ & & Purée & IT & 29 \\
\hline 4 & Tomato sauce & $\mathrm{T}$ & & Purée & IT & 18 \\
\hline 5 & Tomato pulp with basil and onion & $\mathrm{T}$ & & Solid/liquid & IT & 11 \\
\hline 6 & Tomato sauce & $\mathrm{T}$ & & Purée & IT & 9 \\
\hline 7 & Cherry tomatoes in tomato juice & $\mathrm{T}$ & & Solid/liquid & IT & 13 \\
\hline 8 & Tomato sauce & $\mathrm{T}$ & & Purée & IT & 17 \\
\hline 9 & Tomato pulp with basil and onion & $\mathrm{T}$ & & Solid/liquid & IT & 25 \\
\hline 10 & Double-concentrated tomato paste & $\mathrm{T}$ & & Paste & IT & 10 \\
\hline 11 & Tomato pulp & $\mathrm{T}$ & & Solid/liquid & IT & 13 \\
\hline 12 & Tomato sauce & $\mathrm{T}$ & & Purée & IT & 12 \\
\hline 13 & Tomato sauce & $\mathrm{T}$ & Organic & Purée & IT & 30 \\
\hline 14 & Tomato pulp & $\mathrm{T}$ & Organic & Solid/liquid & IT & 18 \\
\hline 15 & Plum tomatoes in tomato juice & $\mathrm{T}$ & & Solid/liquid & IT & 25 \\
\hline 16 & Tomato pulp & $\mathrm{T}$ & & Solid/liquid & IT & 13 \\
\hline 17 & Whole peeled tomatoes in tomato juice & $\mathrm{T}$ & & Solid/liquid & IT & 13 \\
\hline 18 & Chopped tomatoes in tomato juice & $\mathrm{T}$ & Organic & Solid/liquid & IT & 13 \\
\hline 19 & Whole peeled tomatoes in tomato juice & $\mathrm{T}$ & & Solid/liquid & IT & 25 \\
\hline 20 & Cherry tomatoes unpeeled in tomato juice & $\mathrm{T}$ & & Solid/liquid & IT & 13 \\
\hline 21 & Whole peeled tomatoes in tomato juice & $\mathrm{T}$ & & Solid/liquid & IT & 13 \\
\hline 22 & Tomato ketchup & $\mathrm{T}$ & & Purée & IT & 9 \\
\hline 23 & Whole peeled tomatoes in tomato juice & $\mathrm{T}$ & Organic & Solid/liquid & IT & 25 \\
\hline 24 & Cherry tomatoes peeled in tomato juice & $\mathrm{T}$ & & Solid/liquid & IT & 13 \\
\hline 25 & Whole peeled tomatoes in tomato juice & $\mathrm{T}$ & & Solid/liquid & IT & 13 \\
\hline 26 & Tomato sauce & $\mathrm{T}$ & & Purée & IT & 31 \\
\hline 27 & Tomato sauce & $\mathrm{T}$ & & Purée & IT & 19 \\
\hline 28 & Tomato sauce & $\mathrm{T}$ & & Purée & IT & 7 \\
\hline 29 & Tomato sauce & $\mathrm{T}$ & & Purée & IT & 22 \\
\hline 30 & Tomato sauce & $\mathrm{T}$ & & Purée & IT & 31 \\
\hline 31 & Tomato sauce & $\mathrm{T}$ & & Purée & IT & 46 \\
\hline 32 & Tomato sauce & $\mathrm{T}$ & & Purée & IT & 25 \\
\hline 33 & Tomato ketchup & $\mathrm{T}$ & & Purée & IT & 12 \\
\hline 34 & Tomato pulp & $\mathrm{T}$ & Organic & Solid/liquid & IT & 29 \\
\hline 35 & Double-concentrated tomato paste & $\mathrm{T}$ & & Paste & IT & 7 \\
\hline 36 & Triple-concentrated tomato paste & $\mathrm{T}$ & & Paste & IT & 24 \\
\hline 37 & Tomato sauce with basil & TO & & Purée/liquid & IT & 18 \\
\hline 38 & Tomato sauce with olives & TO & & Purée/solid/liquid & IT & 19 \\
\hline 39 & Tomato sauces with clams & TO & & Purée/liquid & IT & 18 \\
\hline 40 & Arrabbiata sauce & то & & Purée/liquid & IT & 14 \\
\hline 41 & Tomato sauce with cheese & TO & & Purée/liquid & IT & 19 \\
\hline 42 & Red pesto & TO & & Purée/liquid & IT & 21 \\
\hline 43 & Tomato sauce with aubergines & TO & & Purée/liquid & IT & 20 \\
\hline 44 & Sun-dried tomatoes paste & TO & & Paste & IT & 21 \\
\hline 45 & Sun-dried cherry tomatoes & TO & & Solid/liquid & IT & 21 \\
\hline 46 & Sun-dried tomatoes & TO & & Solid/liquid & IT & 20 \\
\hline 47 & Sun-dried tomatoes patè & TO & & Paste & IT & 20 \\
\hline 48 & Blood orange, carrot, and lemon juice & $\mathrm{F}$ & & Liquid & IT & 10 \\
\hline 49 & $\begin{array}{l}\text { Pineapple, orange, lemon, and carrot } \\
\text { juice }\end{array}$ & $\mathrm{F}$ & & Liquid & IT & 10 \\
\hline 50 & Apple, grape, and blueberry juice & $\mathrm{F}$ & & Liquid & IT & 8 \\
\hline 51 & Apple and banana purée & $\mathrm{F}$ & Baby food & Purée & IT & 11 \\
\hline 52 & Apple, carrots, and lemon juice & $\mathrm{F}$ & & Liquid & IT & 11 \\
\hline 53 & Apple purée & $\mathrm{F}$ & Baby food & Liquid & IT & 9 \\
\hline 54 & Apple purée & $\mathrm{F}$ & Organic baby food & Purée & $\mathrm{DE}$ & 10 \\
\hline 55 & Apple and banana purée & $\mathrm{F}$ & Organic baby food & Purée & $\mathrm{DE}$ & 8 \\
\hline 56 & Apple purée & $\mathrm{F}$ & Organic baby food & Purée & $\mathrm{DE}$ & 14 \\
\hline 57 & Plums and apple purée & $\mathrm{F}$ & Organic baby food & Purée & $\mathrm{DE}$ & 12 \\
\hline
\end{tabular}

T: tomato-based products containing roughly $100 \%$ tomato content; TO: tomato-based products with a variable content of vegetable oil; F: fruit-based products.

oilseeds and in different tomato products, such as tomato pulp, sauces, and sun-dried tomatoes, as well as in buckwheat, oats, chestnuts, and sesame seeds. AME and TEN were mainly found in grains and oilseeds. TeA was the mycotoxin that reached the highest concentrations and it was mainly found in grains and tomato and tomato products, such as tomato soup, pulp, sauces, and juices, in sun-dried tomatoes, in tomato ketchup, and in fresh tomatoes (EFSA, 2016).

Extraction and clean-up procedures of Alternaria mycotoxins were performed with different techniques, such as solvent partitioning followed by solid phase extraction (SPE) cartridges (Scott, 2001), dispersive liquid-liquid microextraction (Rodriguez-Carrasco, Manes, Berrada, \& Juan, 2016). Solid phase microextraction (SPME) was also applied to determine TeA (Aresta, Cioffi, Palmisano, \& Zambonin, 2003).

QuEChERS (quick, easy, cheap, effective, rugged, and safe) is an alternative method to save time and money-per-sample. It is based on a partitioning step to separate water from acetonitrile and to force analytes into the latter. It was enabled via a salting-out extraction using 
$\mathrm{NaCl}$ or $\mathrm{CH}_{3} \mathrm{COONa}$ coupled with a dehydration step with the addition of $\mathrm{MgSO}_{4}$. QuEChERS is effective for the clean-up of complex matrices and involves a minimum number of steps. When appropriate, it can be combined with other strategies, such as a dispersive solid phase extraction (d-SPE).

The QuEChERS approach was already applied to 25 mycotoxins in cereals (Sun et al., 2016), different kinds of mycotoxins including $\mathrm{Al}$ ternaria toxins in barley (Rubert et al., 2012), and Alternaria toxins in pomegranate (Myresiotis, Testempasis, Vryzas, Karaoglanidis, \& Papadopoulou-Mourkidou, 2015). Moreover, protocols based on QuEChERS methods were successfully used for other contaminants in foods, such as pesticide residues in food (Anastassiades, Lehotay, Stajnbaher, \& Schenck, 2003), drugs in the blood (Plossl, Giera, \& Bracher, 2006), veterinary drugs in animal tissues (Stubbings \& Bigwood, 2009), hormones in food such as meat (Costain, Fesser, McKenzie, Mizuno, \& MacNeil, 2008) and, more recently, it was also tested to determine acrylamide in food (De Paola et al., 2017; Mastovska \& Lehotay, 2006).

Alternaria mycotoxins can be separated using gas chromatography (GC) or high performance liquid chromatography (HPLC) (Lau et al., 2003), and ultra-high-performance liquid chromatography (UHPLC) (Sun et al., 2016). HPLC and UHPLC are preferable for mycotoxins analysis as such techniques do not require derivatisation of the analytes, which is vice versa needed for GC analysis (Myresiotis et al., 2015).

Detection of mycotoxins can be achieved with fluorescence detection (FLD), UV detection, diode array detection (DAD), single mass spectrometry (MS) or tandem MS (MS/MS) (Myresiotis et al., 2015; Ostry, 2008). LC-MS/MS is widely used for mycotoxins analysis and can be coupled either with electrospray ionisation (ESI) or atmospheric pressure chemical ionisation (APCI) interfaces (Lau et al., 2003; Ostry, 2008; Prelle, Spadaro, Garibaldi, \& Gullino, 2013). Lau et al. (2003) compared APCI and ESI for AOH and AME in apple juice and other fruit beverages. ESI used with negative ion detection showed a better resolution and lower noise levels in comparison to APCI.

This study aims to set up a method based on a QuEChERS approach for LC-ESI-MS/MS determination of some Alternaria toxins in order to carry out a screening of tomato-based products, as well as of some fruitbased products, collected from the Italian market. These matrices have been selected in view of the high consumption of tomatoes, tomatobased, and fruit-based products in Italy and in line with EFSA's recommendations on the need for more analytical data in these food categories (EFSA, 2016).

\section{Materials and methods}

\subsection{Sampling}

A total of 57 products were collected from Italian supermarkets with the aim to cover a wide range of tomato-based products, including organic ones. The tomato-based products were 47, from 21 different Italian producers and randomly collected in supermarkets located in different regions of the Northern Italy.

The fruit-based products were selected on the basis of the potential high content in mycotoxins in apple and other fruit products (Ostry, 2008; Scott, 2001). In addition, some baby foods were included. Ten samples from two different producers (an Italian producer and a German one) were randomly collected in supermarkets located in Northern Italy.

The samples (Table 1) were divided into 3 subgroups: T) tomatobased products containing roughly $100 \%$ tomato content (36 samples, including 5 organic products); TO) tomato-based products with a variable content of vegetable oil (11 samples); and F) fruit-based products (10 samples, including 4 organic products and 6 baby foods).

\subsection{Chemicals and standards}

All solvents and reagents were of analytical grade. Acetonitrile (Chromasolv purity for LC-MS), ammonium carbonate (Chromasolv purity for LC-MS), formic acid ( $98 \%$ purity), and methanol (Chromasolv purity for LC-MS) were purchased from Fluka-Sigma-Aldrich ${ }^{\circledR}$ (Milan, Italy). Deionised water was obtained from a Milli-Q purification system (Millipore, Milan, Italy).

The analytical standards of AOH [3,7,9-Trihydroxy-1-methylbenzo [c]chromen-6-one - Alternariol - PubChem CID: 5359485], AME [3,7Dihydroxy-9-methoxy-1-methylbenzo[c]chromen-6-one - Alternariol monomethyl ether - Djalonensone - PubChem CID: 5360741], TEN [(12E)-12-Benzylidene-1,6,7-trimethyl-3-(2-methylpropyl)-1,4,7,10tetrazacyclododecane-2,5,8,11-tetrone - tentoxin - PubChem CID: 5942323], and TeA [3-Acetyl-5-sec-butyl-4-hydroxy-3-pyrrolin-2-one tenuazonic acid - PubChem CID: 54678599] were purchased from Biopure Romer Lab ${ }^{\circledast}$ (Tulln, Austria).

\subsection{Chromatographic method}

\subsubsection{Optimisation}

Six reverse phase (RP) columns were tested to achieve Alternaria toxins separation (Table 2). Different concentrations of an alkali salt, $\left(\mathrm{NH}_{4}\right)_{2} \mathrm{CO}_{3}$, were added to the mobile phase to act as a $\mathrm{pH}$ modifier in order to overcome coelution and peak broadening effects (Reinhold \& Bartels, 2010).

The ESI-MS/MS parameters were optimised with standard solutions of each analyte, introduced individually into the detector. Three precursor-to-product ion transitions (selected reaction monitoring - SRM) in ESI positive mode (in the $100-450 \mathrm{~m} / \mathrm{z}$ range) of the most abundant fragments for each analyte were used. For all SRM transitions, the dwell time was $100 \mathrm{~ms}$.

The approach for peak identification included the comparison of the peak retention times with those obtained using chemical standards and the evaluation of the tandem mass spectroscopy experiments, only for peaks exceeding their own limit of detection (IUPAC, 1978). For each compound, the most intense SRM was used as a quantifier ion $\left(\mathrm{SRM}_{1}\right)$, while the remaining two as qualifier ions $\left(\mathrm{SRM}_{2}\right.$ and $\left.\mathrm{SRM}_{3}\right)$ to confirm the identification of each peak. For TeA, identification was further assured by the use of additional transitions. The relative intensity of each peak was also evaluated and verified to be within an uncertainty range of $\pm 10 \%$.

Table 2

HPLC column used during the chromatographic set up.

\begin{tabular}{|c|c|c|c|c|c|}
\hline Columns & $\begin{array}{l}\text { Stationary } \\
\text { phase }\end{array}$ & $\begin{array}{l}\text { Particle } \\
\text { size }(\mu \mathrm{m})\end{array}$ & $\begin{array}{l}\text { Pore } \\
\text { size } \\
(\AA)\end{array}$ & $\begin{array}{l}\text { Length } \\
(\mathrm{mm})\end{array}$ & $\begin{array}{l}\text { Internal } \\
\text { diameter } \\
(\mathrm{mm})\end{array}$ \\
\hline $\begin{array}{l}\text { Phenomenex } \\
\text { Kinetex }\end{array}$ & $\begin{array}{l}\mathrm{C}_{18} \\
\text { (TMS } \\
\text { endcapped) }\end{array}$ & 5.0 & 100 & 100 & 4.6 \\
\hline $\begin{array}{l}\text { Phenomenex } \\
\text { Luna }\end{array}$ & $\begin{array}{l}\mathrm{C}_{18} \\
\text { (TMS } \\
\text { endcapped) }\end{array}$ & 3.0 & 100 & 150 & 3.0 \\
\hline $\begin{array}{c}\text { Phenomenex } \\
\text { Synergy }\end{array}$ & $\begin{array}{l}\mathrm{C}_{12} \\
\text { (TMS } \\
\text { endcapped) }\end{array}$ & 2.5 & 100 & 50 & 4.6 \\
\hline $\begin{array}{c}\text { Phenomenex } \\
\text { Synergy }\end{array}$ & $\begin{array}{l}\mathrm{C}_{18} \\
\text { (polar } \\
\text { endcapped) }\end{array}$ & 4.0 & 80 & 250 & 4.6 \\
\hline $\begin{array}{l}\text { Phenomenex } \\
\text { Luna }\end{array}$ & $\begin{array}{l}\text { Phenyl-hexyl } \\
\text { (TMS } \\
\text { endcapped) }\end{array}$ & 5.0 & 100 & 150 & 4.6 \\
\hline $\begin{array}{l}\text { Ascentis } \\
\quad \text { Supelco }\end{array}$ & $\begin{array}{l}\mathrm{C}_{8} \\
\text { (TMS } \\
\text { endcapped) }\end{array}$ & 5.0 & 100 & 250 & 4.6 \\
\hline
\end{tabular}




\subsubsection{LC-ESI-MS/MS optimised analytical conditions}

Analyses were carried out by liquid chromatography coupled with mass spectrometry using a RP-LC-ESI-MS/MS system consisting of a vacuum pump, a gas generator (API; Peak Scientific Billerica, MA, USA), a HPLC (Agilent 1200, Agilent, Waldbronn, Germany) equipped with a degasser, a binary pump, an autosampler, a thermostated column compartment, and a triple quadrupole mass spectrometer (API 3200, AB SCIEX ITALIA SRL, Milan, Italy). Nitrogen was used as a desolvation and nebulizing gas.

After filtration $\left(0.2 \mu \mathrm{m} \times 13 \mathrm{~mm}\right.$, PVDS Acrodisc ${ }^{\circledR}$ syringe filter, Aldrich, Milan, Italy), samples were injected (loop $5 \mu \mathrm{L}$ ) onto a $150 \mathrm{~mm} \times 4.60 \mathrm{~mm}$ i.d. $\times 5 \mu \mathrm{m}$ p.s. phenyl-hexyl column (Luna, Phenomenex Srl, Castel Maggiore, BO, Italy) equipped with a guard column Gemini $\mathrm{C}_{6}$-phenyl $4 \times 2 \mathrm{~mm}$ (Phenomenex Srl, Castel Maggiore, BO, Italy).

The mobile phase was prepared by diluting $15 \mathrm{~mL}$ of $\left(\mathrm{NH}_{4}\right)_{2} \mathrm{CO}_{3} 1 \mathrm{M}$ to $1 \mathrm{~L}$ with $\mathrm{MeOH}$. The elution was carried out according to the following profile: from $0.00 \mathrm{~min}$ to $6.30 \mathrm{~min}$ with a flow rate of $0.4 \mathrm{~mL} /$ min and from 6.31 to $15 \mathrm{~min}$ with a flow rate of $1.0 \mathrm{~mL} / \mathrm{min}$ at room temperature.

Standard stock solutions $(100 \mathrm{mg} / \mathrm{L})$ were made up for each substance using $\mathrm{HCOOH} 0.1 \%$ in ACN as solvent.

Quantification was performed by external standard calibration, and the obtained results were corrected based on recovery tests. The chromatograms were acquired and processed by Analyst software, version 1.5 (AB Sciex Italia S.r.l., Milan, Italy).

\subsection{Method for the Alternaria toxins extraction}

\subsubsection{Optimisation of the QuEChERS method}

To optimise the protocol of extraction, the effects of two different QuEChERS tools (Agilent QuEChERS pouches containing $\mathrm{MgSO}_{4}$ $4.0 \mathrm{~g}+\mathrm{NaCl} 0.5 \mathrm{~g}$ and Waters QuEChERS tubes containing $\mathrm{MgSO}_{4}$ $6.0 \mathrm{~g}+\mathrm{CH}_{3} \mathrm{COONa} 1.5 \mathrm{~g}$ ), different sample weight $(1.0 \mathrm{~g}, 2.5 \mathrm{~g}$, and $5.0 \mathrm{~g}$ ), purification by dispersive SPE (d-SPE), addition of different amounts of water ( 0 and $2.5 \mathrm{~mL}$ ), types of solvent (ACN and $\mathrm{HCOOH}$ $0.1 \%$ in $\mathrm{ACN}$ ), use of the ceramic homogenizer, time of shaking ( $3 \mathrm{~min}$ and $10 \mathrm{~min}$ ), and rotational speed (300 rpm and $500 \mathrm{rpm}$ ) were assessed through recovery tests.

All the optimisation tests were carried out on the same sample of tomato pulp (TP; sample number 11 from Table 1) that showed concentrations below LOD for all the analytes. TP was spiked with a mixture of the four Alternaria toxins $(250 \mu \mathrm{g} / \mathrm{mL}$ each) and allowed to stand for $30 \mathrm{~min}$ to enhance the interaction between the matrix and the analytes.

\subsubsection{Optimised QUEChERS protocol for the Alternaria toxins analysis}

Alternaria toxins determination was carried out on the samples using the method described by De Paola et al. (2017) for acrylamide extraction and by Myresiotis et al. (2015) for Alternaria mycotoxins extraction in pomegranate, and both were slightly modified to adapt the protocols to the specific matrices.

All the samples were either homogenous or homogenised with an Ultraturrax T25 (IKA, Milan, Italy), and their final consistency was liquid or semisolid. The sampling was carried out at different levels of depth. Subsequently, from the properly homogenised joined aliquots, $2.50 \mathrm{~g}$ were transferred into a 50 -mL Falcon tube with the addition of a ceramic homogenizer for QuEChERS. $10 \mathrm{~mL}$ of $\mathrm{HCOOH} 0.1 \%$ in ACN and $2.5 \mathrm{~mL}$ of Milli-Q water were added. The tube was thoroughly shaken for 1 min on a vortex (RX3, Velp Scientifica, Usmate Velate, MB, Italy). A QuEChERS pouch composed of $\mathrm{MgSO}_{4} 4.0 \mathrm{~g}+\mathrm{NaCl} 0.5 \mathrm{~g}$ was added and hand-shaken for $1 \mathrm{~min}$, and then with a shaker (Unimax 2010, Heidolph Instruments Italia S.r.l., Milan, Italy) at room temperature for $10 \mathrm{~min}$ at $500 \mathrm{rpm}$ to allow the mycotoxins to migrate into the acetonitrile phase. The tube was then centrifuged for $3 \mathrm{~min}$ at $3200 \mathrm{rpm}$ at $0{ }^{\circ} \mathrm{C}$ to improve the separation of the two layers. The upper layer was filtered through a $0.20 \mu \mathrm{m}$ polyethersulfone (PES) membrane and transferred into a $2 \mathrm{~mL}$ vial, which was loaded into an autosampler chamber at a controlled temperature. Each sample extraction was carried out three times for all the tests of the method optimisation.

\subsection{Method evaluation}

2.5.1. Evaluation of linearity, limit of detection and lower limit of quantification (detectability), intra-day and inter-day repeatability (precision), and recovery test (trueness)

Standard stock solutions $(100 \mathrm{mg} / \mathrm{L})$ were made up for each substance using $\mathrm{HCOOH} 0.1 \%$ in ACN as solvent. A series of solutions of increasing concentration were prepared to evaluate the linearity of the instrumental response at the expected concentration range for each analyte.

Limit of detection (LOD) and lower limit of quantification (LLOQ) were calculated as follows (Miller \& Miller, 2010):

$\mathrm{y}_{\text {LOD }}=\mathrm{y}_{\text {Noise }}+3 \mathrm{~s}_{\text {Noise }}$ and $\mathrm{y}_{\text {LLOQ }}=\mathrm{y}_{\text {Noise }}+6 \mathrm{~s}_{\text {Noise }}$

Precision was evaluated using two different repeatability tests. An intra-day precision test was carried out by extracting and injecting a contaminated sample (tomato sauce) ten times to evaluate the repeatability through the stability of the chromatographic system. An interday precision test was carried out by spiking $2.5 \mathrm{~g}$ TP with $1 \mathrm{~mL}$ of a standard solution of toxins $(250 \mu \mathrm{g} / \mathrm{mL}$ each). It was extracted with the optimised method and injected three times. The test was repeated on three consecutive days in order to evaluate, aside from the stability of the chromatographic system, also the method repeatability on different days.

Trueness was evaluated through a recovery test on four samples by spiking a known amount of a standard solution of toxins $(250 \mu \mathrm{g} / \mathrm{mL}$ each). Representative samples for each subgroup were selected. For tomato-based products, two samples were evaluated, one for low and one for high concentration. The other samples of the same subgroup were considered completely equivalent, because of their similar consistency and homogeneity.

\section{Results and discussion}

\subsection{Mass spectrometry parameters setup}

The "compound dependent" parameters - declustering potential (DP), entrance potential (EP), collision energy (CE), collision cell entrance potential (CEP), collision cell exit potential (CXP) - were set up through direct infusion in the spectrometer of a $5 \mathrm{mg} / \mathrm{L}$ solution of each standard compound (Table 3). DP and EP were optimised for the parent ion, while CE and CXP for the parent ion and the product ions. For each compound, except TeA, three product ions are considered, corresponding to one quantifier transition $\left(\mathrm{SRM}_{1}\right)$ and two qualifier transitions $\left(\mathrm{SRM}_{2}\right.$ and $\left.\mathrm{SRM}_{3}\right)$.

The flow injection mode (FIA) was used for the optimisation of the "source dependent" parameters - curtain gas (CUR), collision activated dissociation (CAD), ion spray voltage (ISV), nebulizer gas (GS1), heater gas (GS2), and source temperature (TEM) - by injecting the same standard compounds with no column between the injector and detector and using the HPLC pump to propel the mobile phase. Optimised parameters for each compound are showed in Table 3. Some conditions were constant for all the analytes: CAD, 5 ; TEM, $650^{\circ} \mathrm{C}$; GS1, $40 \mathrm{psi}$; GS2, 30 psi.

High sensitivity was obtained in ESI positive mode for all compounds, as already reported (Rodriguez-Carrasco et al., 2016). For AOH, AME, and TEN, the same parent ion (protonated molecular ion $[\mathrm{M}+\mathrm{H}]^{+}$) was obtained with high sensitivity. For AME and TEN, the most intense SMR transitions corresponded to those reported by Rodriguez-Carrasco et al. (2016), while for AOH the most intense SMR 
Table 3

List of the retention times $\left(t_{\mathrm{R}}\right)$, parent ions, and SRM transitions obtained after MS parameters optimisation and main MS parameters optimised for each compound.

\begin{tabular}{|c|c|c|c|c|c|c|c|c|c|c|}
\hline Analyte & $t_{\mathrm{R}}(\min )$ & Parent ion $(m / z)$ & $\mathrm{SRM}_{1}, \mathrm{SRM}_{2}$, and $\mathrm{SRM}_{3}(m / z)$ & CUR (PSI) & ISV (V) & $\mathrm{DP}(\mathrm{V})$ & CE (V) & $\mathrm{CXP}(\mathrm{V})$ & $\mathrm{EP}(\mathrm{V})$ & $\mathrm{CEP}(\mathrm{V})$ \\
\hline \multirow[t]{3}{*}{$\mathrm{AOH}$} & 4.2 & 259.2 & 259.2/185.2 Q & 15 & 4700 & 71.98 & 43.98 & 4.00 & 8.00 & 28.77 \\
\hline & & {$[\mathrm{M}+\mathrm{H}]^{+}$} & $259.2 / 128.1 \mathrm{q}$ & & & & 67.17 & & & \\
\hline & & & $259.2 / 213.1 \mathrm{q}$ & & & & 38.92 & & & \\
\hline \multirow[t]{3}{*}{ AME } & 5.2 & 273.1 & 273.1/128.1 Q & 15 & 4700 & 75.07 & 65.53 & 4.00 & 8.10 & 29.14 \\
\hline & & {$[\mathrm{M}+\mathrm{H}]^{+}$} & $273.1 / 115.1 \mathrm{q}$ & & & & 78.0 & & & \\
\hline & & & $273.1 / 184.2 \mathrm{q}$ & & & & 52.12 & & & \\
\hline \multirow[t]{3}{*}{ TEN } & 6.0 & 415.2 & $415.2 / 312.2 \mathrm{Q}$ & 15 & 4700 & 56.83 & 28.38 & 5.22 & 8.00 & 32.98 \\
\hline & & {$[\mathrm{M}+\mathrm{H}]^{+}$} & $415.2 / 256.1 \mathrm{q}$ & & & & 41.36 & 4.00 & & \\
\hline & & & $415.2 / 302.1 \mathrm{q}$ & & & & 20.48 & 4.77 & & \\
\hline \multirow[t]{6}{*}{ TeA } & 10.3 & 231.0 & 231.0/203.0 Q & 10 & 5000 & 65.22 & 18.35 & 5.79 & 10.0 & 28.01 \\
\hline & & {$\left[\mathrm{M}+\mathrm{H}+\mathrm{CH}_{3} \mathrm{OH}\right]^{+}$} & $231.0 / 157.0 \mathrm{q}$ & & & & 10.25 & 4.00 & & \\
\hline & & & & & & & 28.64 & 4.00 & & \\
\hline & & 198.2 & $198.2 / 125.1 q$ & 10 & 5000 & 37.90 & 23.18 & 4.00 & 7.80 & 27.12 \\
\hline & & {$[M+H]^{+}$} & $198.2 / 153.2 q$ & & & & 22.69 & & & \\
\hline & & & $198.2 / 139.1 q$ & & & & 23.44 & & & \\
\hline
\end{tabular}

AOH: alternariol; AME: alternariol monomethyl ether; TEN: tentoxin; TeA: tenuazonic acid.

$\mathrm{SRM}_{1}$ : selected reaction monitoring for the quantifier ion; $\mathrm{SRM}_{2}$ and $\mathrm{SRM}_{3}$ : selected reaction monitoring for the qualifier ions; CUR: curtain gas; ISV: ion spray voltage; DP: declustering potential; CE: collision energy; CXP: collision cell exit potential; EP: entrance potential; CEP: collision cell entrance potential; Q: quantifier transition; q: qualifier transition.

In Italics, optimised parameters for $\mathrm{TeA}[\mathrm{M}+\mathrm{H}]^{+}$parent ion, which was monitored for the sole purpose of identification.

transition $(259 \rightarrow 185 \mathrm{~m} / \mathrm{z})$ corresponded to the qualifier ion reported by the same authors.

Due to unsatisfactory response of TeA protonated molecular ion $[\mathrm{M}+\mathrm{H}]^{+}(198 \mathrm{~m} / z)$, the adduct with methanol $\left[\mathrm{M}+\mathrm{H}+\mathrm{CH}_{3} \mathrm{OH}\right]^{+}$ $(231 \mathrm{~m} / \mathrm{z})$ was considered for its detection due to a better response (Table 3), along with one qualifier ion $\left(\mathrm{SRM}_{2}\right)$. The $[\mathrm{M}+\mathrm{H}]^{+}$parent ion and its corresponding product ions (Hickert, Bergmann, Ersen, Cramer, \& Humpf, 2016) were monitored for the sole purpose of identification.

\subsection{Chromatographic setup}

$\mathrm{C}_{18}$ and, to a lesser extent, $\mathrm{C}_{12}$ stationary phases provided a low resolution of the peaks. The $\mathrm{C}_{8}$ stationary phase caused higher retention of TeA in the column with a large increase of its run time.

The best separation of the analytes was obtained with a TMS-endcapped phenyl-hexyl column. This stationary phase was suitable for the separation of the aromatic rings of the Alternaria mycotoxins through the combination of aromatic, hydrophobic, and dipolar interactions (Ostry, 2008). Tölgyesi et al. (2015) also compared different RP columns [cyano (ES-CN), phenyl-hexyl, and $\mathrm{C}_{18}$ ] for Alternaria mycotoxins and citrinin determination in tomatoes. The authors concluded that the phenyl-hexyl column provided a good separation of the peaks.

Pure $\mathrm{MeOH}$ was tested as a mobile phase, resulting in non-symmetric peaks. According to Reinhold and Bartels (2010), this problem can be overcome through a $\mathrm{pH}$ modification by adding a $\left(\mathrm{NH}_{4}\right)_{2} \mathrm{CO}_{3}$ solution to $\mathrm{MeOH}$. Three different concentrations of $\left(\mathrm{NH}_{4}\right)_{2} \mathrm{CO}_{3}$ were compared: $3 \mathrm{mM}, 6 \mathrm{mM}$, and $15 \mathrm{mM}$. Better performances were obtained increasing the mobile phase $\mathrm{pH}$ by adding $\left(\mathrm{NH}_{4}\right)_{2} \mathrm{CO}_{3} 15 \mathrm{mM}$. The optimal pH was verified to be 8.8 (Fig. 1A). pH higher than 9.0 led to a coelution of AME and TEN (Fig. 1B) and the shift of the TeA retention time, while a pH lower than 8.5 brought about a shift of the $\mathrm{AOH}$ retention time with a consequent peak broadening (Fig. 1C). The flow was increased from $400 \mu \mathrm{L} / \mathrm{min}$ up to $1000 \mu \mathrm{L} / \mathrm{min}$ after the elution of the first three peaks $(6.30 \mathrm{~min})$ in order to reduce a broadening effect on the TeA peak (Fig. 1A).

\subsection{Optimisation of the QuEChERS extraction method for Alternaria toxins}

3.3.1. Effect of the type of QuEChERS pouch, sample weight and purification by $d$-SPE on recoveries

The effect of two different QuEChERS tools (i.e. $4 \mathrm{~g} \mathrm{MgSO}_{4}+0.5 \mathrm{~g}$ $\mathrm{NaCl}$ and $6 \mathrm{~g} \mathrm{MgSO}_{4}+1.5 \mathrm{~g} \mathrm{CH}_{3} \mathrm{COONa}$ ) was tested on TP using $1.0 \mathrm{~g}$, $2.5 \mathrm{~g}$, and $5.0 \mathrm{~g}$, without added water. Recoveries (\%) were calculated on TP spiked with $1 \mathrm{~mL}$ of a mix of standard solution of toxins ( $250 \mu \mathrm{g}$ / mL each) (Table 4).

The pouch containing $6 \mathrm{~g} \mathrm{MgSO}_{4}+1.5 \mathrm{~g} \mathrm{CH}_{3} \mathrm{COONa}$ provided better recoveries for AOH, AME, and TEN (except for $1.0 \mathrm{~g}$ of sample), but it was not able to extract TeA in any case, and for this reason it was discarded.

The best recoveries obtained using the QuEChERS pouch containing $4 \mathrm{~g} \mathrm{MgSO}_{4}+0.5 \mathrm{~g} \mathrm{NaCl}$ were achieved using $1.0 \mathrm{~g}$ and $2.5 \mathrm{~g}$ of the sample. However, being lower than $60 \%$, the recoveries were considered unsatisfactory for AOH, AME, and TEN (European Commission, 2006). In the subsequent optimisation steps, it was decided to use a weight of $2.5 \mathrm{~g}$ to have a more representative sample and to reduce the dilution factor that affected the method detectability.

The d-SPE step brought about the total loss of TeA and for this reason it was not included in this procedure. At high $\mathrm{pH}$ values, due to $\mathrm{CH}_{3} \mathrm{COONa}$ (Waters pouch) and primary-secondary amines (d-SPE), TeA was present in the anionic form and did not migrate in the solvent (ACN).

3.3.2. Effect of the addition of water, the type of solvent, the use of the ceramic homogenizer, and conditions of shaking on recoveries

The effects of the use of different amounts of water and the addition of $\mathrm{HCOOH}(0.1 \%)$ to the extraction solvent (pure ACN) are showed in Table 5. A ceramic homogenizer (not present in the previous test) was placed in the tube and kept throughout the analysis. It helped to break up salt agglomerates, thus promoting a consistent sample extraction.

Trials were carried out on $2.5 \mathrm{~g}$ of TP spiked with $1 \mathrm{~mL}$ of standard solution of toxins $(250 \mu \mathrm{g} / \mathrm{mL}$ each). ACN was used as the extraction solvent and the sample was shaken for $3 \mathrm{~min}$ at $300 \mathrm{rpm}$ on an orbital shaker. The addition of $2.5 \mathrm{~mL}$ of water provided better recoveries, mainly for $\mathrm{AOH}(63 \%)$ and TEN (63\%), while for AME it was lower $(56 \%)$ than the samples prepared with no water. The recovery of TeA was about $118 \%$ for the samples prepared with no water with a worse standard deviation in comparison with the samples prepared with $2,5 \mathrm{~mL}$ of water. To improve the recoveries, $\mathrm{HCOOH}(0.1 \%)$ was added to ACN. In fact, some studies showed that the acidification of the solvent with $\mathrm{HCOOH}(0.1 \%)$ increased the extraction yield of TeA by reducing its anionic form (Ostry, 2008; Scott, 2001).

The recovery of TeA (95\%), as well as of AME (64\%), were improved using the acidic condition of the mobile phase, while the result for TEN was almost unchanged and showed a little decrease for $\mathrm{AOH}$. The acidification of the mobile phase was preferred. However, as recoveries under these conditions were in some cases near the limits of acceptability, it was decided to adopt a further modification in order to 

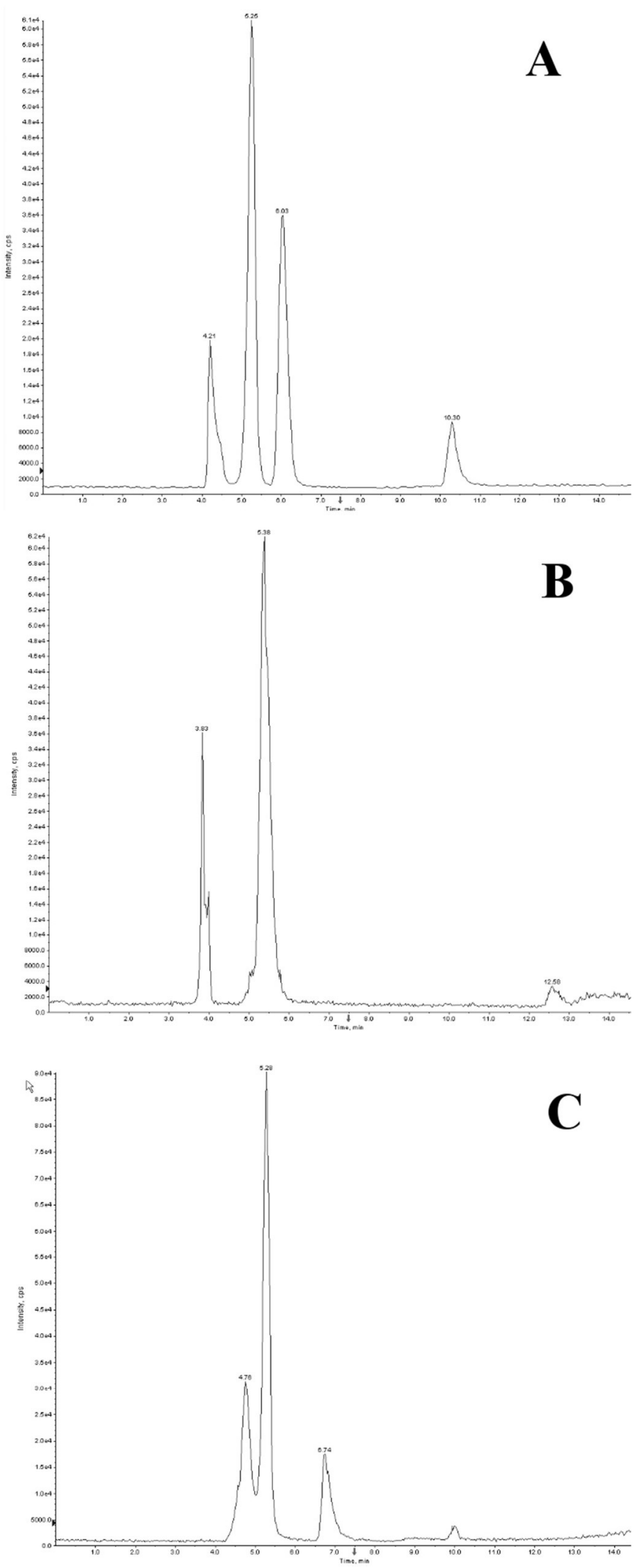

Fig. 1. Chromatogram (A) of a mixture of standard of AOH $(125 \mu \mathrm{g} / \mathrm{mL})$, AME $(125 \mu \mathrm{g} /$ $\mathrm{mL})$, TEN $(125 \mu \mathrm{g} / \mathrm{mL})$, and TeA $(500 \mu \mathrm{g} / \mathrm{mL})$ at the optimised analytical conditions (pH 8.80); chromatogram of a mixture of standard of $\mathrm{AOH}(312.5 \mu \mathrm{g} / \mathrm{mL}$ ), AME $(312.5 \mu \mathrm{g} / \mathrm{mL})$, TEN $(312.5 \mu \mathrm{g} / \mathrm{mL})$, and TeA $(1250 \mu \mathrm{g} / \mathrm{mL})$ at $\mathrm{pH} 9.45$ (B) and at $\mathrm{pH} 8.40$ (C). increase the extractive capacity of the solvent.

Two different conditions of shaking, $3 \mathrm{~min}$ at $300 \mathrm{rpm}$, and $10 \mathrm{~min}$ at $500 \mathrm{rpm}$, were compared using $2.5 \mathrm{~g}$ of sample and $0.1 \%$ of $\mathrm{HCOOH}$ in ACN, as an extraction solvent. Trials were carried out on TP spiked with $1 \mathrm{~mL}$ of a standard solution of toxins $(250 \mu \mathrm{g} / \mathrm{mL}$ each). Results showed (Table 5) that increasing the shaking time and the rotational speed to up to $10 \mathrm{~min}$ and $500 \mathrm{rpm}$, respectively, the recoveries of all the substances improved. The yields of extraction did not further increase with longer shaking times. The optimisation of the method yielded mean recoveries for three compounds above $60 \%$ (AOH, AME, and TEN) and one above $90 \%(\mathrm{TeA})$.

3.4. Validation of linearity of response, detectability, precision, and trueness of the method

For all the compounds, the coefficients of determination $\left(\mathrm{R}^{2}\right)$ above 0.99 (Table 6) showed a satisfactory linear correlation between concentration and response, also confirmed by a visual inspection (Miller \& Miller, 2010). An F-test was also carried out to evaluate the acceptability of the linear models (Araujo, 2009; Miller \& Miller, 2010). For all compounds, the $P$-value returned from the $F$-test was considerably lower than $10^{-3}$ (Table 6), thus confirming the effectiveness of each model.

As for detectability, LOD values were found to be $2.5 \mu \mathrm{g} / \mathrm{kg}$ for $\mathrm{AOH}$ and AME and even lower for TEN $(0.25 \mu \mathrm{g} / \mathrm{kg})$. For TeA, detectability limits were higher (LOD $=20 \mu \mathrm{g} / \mathrm{kg} ; \mathrm{LLOQ}=40 \mu \mathrm{g} / \mathrm{kg}$ ). The method included a sample dilution (dilution factor: 4 ) and for this reason LODs and LLOQs were multiplied for that factor (Table 6).

The method showed worse values of detectability if compared to other studies on tomato-based products, in particular to a method based on the dispersive liquid-liquid microextraction (DLLME) combined with LC-ESI-MS/MS for AOH, AME, and TEN with LODs and LLOQs in the range $0.7-3.5 \mathrm{ng} / \mathrm{g}$ (Rodriguez-Carrasco et al., 2016), and to a method for TeA, based on the liquid extraction coupled with an HPLCMS/MS approach, where a LOD of $0.38 \mu \mathrm{g} / \mathrm{kg}$ and a LLOQ of $1.28 \mu \mathrm{g} / \mathrm{kg}$ were obtained (Hickert et al., 2016). However, in the former study, TeA was not determined and in the latter one the detectability for TEN determination was comparable to the value presented in this work. In another study, the detectability of a method based on the QUECHERS approach combined with UPLC-MS/MS on tomato products ranged from 3.0 to $18.3 \mu \mathrm{g} / \mathrm{kg}$ for LOD and from 9.8 to $61.5 \mu \mathrm{g} / \mathrm{kg}$ LLOQ (Walravens et al., 2016). These values were higher than LOD and LLOQ found in the present work for AOH, AME, and TEN, i.e. from 1.0 to $10 \mu \mathrm{g} / \mathrm{kg}$, and from 4.0 to $20 \mu \mathrm{g} / \mathrm{kg}$, respectively (Table 6).

EFSA (2016) reported the minimum and maximum LLOQs for the four toxins in different categories based on a European data collection. Considering only the categories relevant to this work (i.e. 'vegetables and vegetable products, including fungi', 'fruit and fruit products', 'fruit and vegetable juice', 'herbs, spices and condiments', and 'food for infants and young children'), the values reported by EFSA (2016) are comparable to those showed in Table 6 for AOH, AME, and TEN, with little exceptions.

Conversely, the maximum LLOQs of TeA for the same food categories ranged from $50 \mu \mathrm{g} / \mathrm{kg}$ and $66 \mu \mathrm{g} / \mathrm{kg}$ (EFSA, 2016). These values are about 3 times lower than those found in the present method. Nonetheless, the method is considered suitable for the analysis of TeA in tomato-based products. In fact, considering the occurrence data published by EFSA (2016), the mean values found in tomato-based products are much higher than the LLOQ of the present method. Mean values were as high as $211.8 \mu \mathrm{g} / \mathrm{kg}$ for tomato purée and $229.3 \mu \mathrm{g} / \mathrm{kg}$ for sun-dried tomatoes, confirming that the detectability of the method was sufficient for TeA. In the categories 'fruit and vegetable juices' and 'food for infants and young children' the lower mean concentrations found were $0.2 \mu \mathrm{g} / \mathrm{kg}$ and $4.2 \mu \mathrm{g} / \mathrm{kg}$, respectively (EFSA, 2016). For these food categories the detectability of the method for TeA needs to be improved. 
Table 4

Comparison of recoveries (\%) of Alternaria toxins obtained with two QuEChERS pouches ( $4 \mathrm{~g} \mathrm{MgSO}_{4}+0.5 \mathrm{~g} \mathrm{NaCl} \mathrm{vs.} 6 \mathrm{~g} \mathrm{MgSO}_{4}+1.5 \mathrm{~g} \mathrm{CH} \mathrm{COONa}_{3}$ using different sample weights $(1.0 \mathrm{~g}, 2.5 \mathrm{~g}$, and $5.0 \mathrm{~g})$, with and without primary secondary amine (PSA).

\begin{tabular}{|c|c|c|c|c|c|}
\hline & TP $(g)$ & $\mathrm{AOH}(\%)$ & AME (\%) & TEN (\%) & TeA (\%) \\
\hline \multirow[t]{6}{*}{$4 \mathrm{~g} \mathrm{MgSO}_{4}+0.5 \mathrm{~g} \mathrm{NaCl}$} & 1.0 & $32.2 \pm 4.3$ & $43.9 \pm 2.7$ & $38.9 \pm 2.4$ & $75.8 \pm 7.3$ \\
\hline & $1.0+$ PSA & $4.2 \pm 3.8$ & $31.9 \pm 1.8$ & $35.5 \pm 3.2$ & 0.0 \\
\hline & 2.5 & $29.0 \pm 2.9$ & $35.0 \pm 1.3$ & $35.8 \pm 2.5$ & $71.2 \pm 6.8$ \\
\hline & $2.5+$ PSA & $12.0 \pm 2.9$ & $37.6 \pm 2.0$ & $35.1 \pm 3.3$ & 0.0 \\
\hline & 5.0 & $30.8 \pm 3.6$ & $25.1 \pm 1.7$ & $32.3 \pm 3.1$ & $61.2 \pm 8.7$ \\
\hline & $5.0+$ PSA & $19.4 \pm 3.9$ & $28.5 \pm 2.4$ & $33.6 \pm 3.4$ & 0.0 \\
\hline \multirow[t]{6}{*}{$6 \mathrm{~g} \mathrm{MgSO}_{4}+1.5 \mathrm{~g} \mathrm{CH}_{3} \mathrm{COONa}$} & 1.0 & $42.9 \pm 3.0$ & $15.3 \pm 2.2$ & $43.8 \pm 3.5$ & 0.0 \\
\hline & $1.0+$ PSA & $22.8 \pm 4.3$ & $39.1 \pm 2.4$ & $40.7 \pm 3.7$ & 0.0 \\
\hline & 2.5 & $39.1 \pm 2.7$ & $40.2 \pm 1.8$ & $36.5 \pm 3.1$ & 0.0 \\
\hline & $2.5+\mathrm{PSA}$ & $23.1 \pm 3.1$ & $36.3 \pm 2.1$ & $37.9 \pm 2.8$ & 0.0 \\
\hline & 5.0 & $32.9 \pm 4.2$ & $37.9 \pm 2.2$ & $32.9 \pm 2.3$ & 0.0 \\
\hline & $5.0+$ PSA & $35.6 \pm 4.0$ & $34.5 \pm 3.4$ & $39.3 \pm 3.5$ & 0.0 \\
\hline
\end{tabular}

AOH: alternariol; AME: alternariol monomethyl ether; TEN: tentoxin; TeA: tenuazonic acid. TP: sample of tomato pulp that showed concentrations $<$ LOD for all the analytes.

The intra-day precision was performed on a contaminated sample (tomato sauce) extracted and injected ten times in the same day. Concentrations above LLOQ were found only for TeA and its precision expressed as RSD was $\mathbf{8 . 5 0 \%}$. The inter-day precision was evaluated by relative standard deviations (RSD) for each analyte and determined on TP spiked with a known amount of a standard solution of toxins. RSDs were below $\pm 10 \%$ for all the analytes (Table 6 ). For a confidence level of $95 \%$ and coverage factor $(\mathrm{k})=2$, the method has an uncertainty lower than $\pm 20 \%$ (Miller \& Miller, 2010).

The trueness (Feinberg, 2007) was evaluated using a recovery test carried out on each type of food subgroup. The recovery was very satisfactory for TeA, ranging from $98.8 \%$ to $108.9 \%$, while the other compounds showed recoveries below $80 \%$ in some cases, but always above $60 \%$ (Table 6). For this reason, the concentrations were corrected on the basis of the recovery tests data obtained for the corresponding food subgroup.

\subsection{Samples analysis}

All the samples showed values below LODs of AOH, AME, and TEN. For $\mathrm{AOH}$ and $\mathrm{AME}$, the obtained results were consistent with the data available in the literature, reporting values below the limits of detectability (Motta \& Valente Soares, 2001; Rodriguez-Carrasco et al., 2016) or very low values $(<15 \mu \mathrm{g} / \mathrm{mL}$ ) (Asam, Konitzer, \& Rychlik, 2011; Hickert et al., 2016; Terminiello, Patriarca, Pose, \& Fernandez Pinto, 2006; Walravens et al., 2016).

A study reported the detection of TEN in 9 out of 85 samples of tomato products in a range of concentration between 1 and $3 \mu \mathrm{g} / \mathrm{kg}$ (Noser, Schneider, Rother, \& Schmutz, 2011). However, TEN was not detected or was found in concentrations that did not exceed its LLOQ in tomato-based products (Hickert et al., 2016; Rodriguez-Carrasco et al., 2016; Walravens et al., 2016).

TeA was the only toxin found above the limits of detectability in ten samples. Its concentration was below LLOQ in seven samples (one canned tomato pulp, one tomato sauce, one ketchup, two double concentrated tomato pastes, one triple concentrated tomato paste, one dried tomato pâté). Three samples in the category of tomato-based products, i.e. one organic tomato sauce (sample number 13 from Table 1), one tomato sauce (sample number 30 from Table 1), and one organic tomato pulp (sample number 34 from Table 1), showed concentrations of TeA as high as $167 \pm 14 \mu \mathrm{g} / \mathrm{kg}, 814 \pm 69 \mu \mathrm{g} / \mathrm{kg}$, and $225 \pm 19 \mu \mathrm{g} / \mathrm{kg}$, respectively.

These results confirm the data found in the literature that indicate TeA as the toxin occurring at the highest concentration, especially in tomato-based products (EFSA, 2016). Its maximum concentrations found in the literature were $460 \mu \mathrm{g} / \mathrm{kg}$ (Hickert et al., 2016), $333 \mu \mathrm{g} / \mathrm{kg}$ (Walravens et al., 2016), and $541 \mu \mathrm{g} / \mathrm{kg}$ (Lohrey, Marschik, Cramer, \& Humpf, 2012) in tomato-based products. The concentration was as high as $2330 \mu \mathrm{g} / \mathrm{kg}$ in a freeze-dried tomato powder (Lohrey et al., 2012).

The determination of TeA is very challenging because of its low MS detection response, therefore a derivatisation step with 2,4-dinitrophenylhydrazine was proposed to increase its response (Tölgyesi et al., 2015). However, the QuEChERS approach aimed to reduce the use of solvents and analysis times, thus the derivatisation step was not considered. In addition, the QuEChERS method proved to be suitable for TeA recovery.

It is not clear whether the fungi proliferation and, in turn, the mycotoxins concentrations took advantage of the organic farming systems (Sobieralski, Siwulski, \& Sas-Golak, 2013). However, Malmauret, Parent-Massin, Hardy, and Verger (2002) found higher concentrations of deoxynivalenol (DON) and nivalenol (NIV) in organic foodstuffs compared to non-organic ones (DON in wheat: $106 \mu \mathrm{g} / \mathrm{kg}$ vs. $55 \mu \mathrm{g} / \mathrm{kg}$, respectively; DON in barley: $69 \mu \mathrm{g} / \mathrm{kg}$ vs. $41 \mu \mathrm{g} / \mathrm{kg}$, respectively; NIV in barley: $83 \mu \mathrm{g} / \mathrm{kg}$ vs. $10 \mu \mathrm{g} / \mathrm{kg}$, respectively). The contamination of crops with mycotoxins is likely to cause contaminated processed products (Drusch \& Ragab, 2003).

For the fruit-based samples, all the analytes showed values below LOD. These results are consistent with the low average values reported in the literature for $\mathrm{AOH}$ and AME. In fact, the maximum values reported in EFSA (2016) are $5.6 \mu \mathrm{g} / \mathrm{kg}$ for $\mathrm{AOH}$ and $1.7 \mu \mathrm{g} / \mathrm{kg}$ for AME,

Table 5

Comparison of recoveries (\%) of Alternaria toxins obtained with different amount of $\mathrm{H}_{2} \mathrm{O}(0 \mathrm{~mL}$ and $2.5 \mathrm{~mL}$ ), different extraction solvents (ACN and $\mathrm{HCOOH} 0.1 \%$ in ACN), and different time of shaking and revolution per minute (rpm). One ceramic homogenizer was included in each tube. Test was performed on a sample of tomato pulp that showed concentrations < LOD for all the analytes (TP).

\begin{tabular}{|c|c|c|c|c|c|c|}
\hline Extraction solvent & $\mathrm{H}_{2} \mathrm{O}$ added $(\mathrm{mL})$ & Time of shaking (min) & $\mathrm{AOH}(\%)$ & AME (\%) & TEN (\%) & TeA (\%) \\
\hline $\mathrm{ACN}$ & 0 & $3(300 \mathrm{rpm})$ & $52.3 \pm 3.6$ & $69.8 \pm 4.4$ & $61.2 \pm 3.2$ & $117.9 \pm 15.7$ \\
\hline $\mathrm{ACN}$ & 2.5 & $3(300 \mathrm{rpm})$ & $62.6 \pm 3.2$ & $55.6 \pm 2.8$ & $62.9 \pm 3.6$ & $87.0 \pm 3.8$ \\
\hline $\mathrm{HCOOH} 0.1 \%$ in ACN & 2.5 & $3(300 \mathrm{rpm})$ & $60.0 \pm 2.3$ & $64.1 \pm 0.5$ & $62.5 \pm 1.3$ & $94.8 \pm 1.4$ \\
\hline $\mathrm{HCOOH} 0.1 \%$ in $\mathrm{ACN}$ & 2.5 & $10(500 \mathrm{rpm})$ & $64.4 \pm 1.5$ & $69.3 \pm 1.9$ & $64.2 \pm 3.0$ & $98.8 \pm 5.5$ \\
\hline
\end{tabular}

AOH: alternariol; AME: alternariol monomethyl ether; TEN: tentoxin; TeA: tenuazonic acid. 
both below the LODs calculated for AOH and AME.

\section{Conclusions}

The QuEChERS method for Alternaria mycotoxins extraction showed to be an easy, fast, and cheap "one-pot" sample procedure. This approach needs a reduced amount of solvent compared to liquid-liquid extraction and this technique does not include the use of disposable cartridges as the solid phase extraction does. The use of an organic solvent (acetonitrile) as an extraction solvent was particularly appropriate for TeA extraction, in combination with the acidic medium that reduced its anionic form and increased its recovery to values close to $100 \%$.

Detectability of the method was satisfactory for AOH, AME, and TEN, while it was only partially satisfactory for TeA. However, TeA is usually present in higher concentrations in the samples. In this perspective, the present method showed reliability to criticalities related to the TeA presence in tomato-based samples.

The research on Alternaria toxins is limited by an uncompleted characterisation of the over 70 toxins produced by the fungi and the lack of most analytical standards. The availability of the standards would foster research to improve the method for a full screening of Alternaria toxins on food products subject to contamination.

\section{Acknowledgements}

The authors wish to thank Dr. Laura Munari (English-language reviewer), Dr. Filippo Genovese and Dr. Diego Pinetti (C.I.G.S. of the University of Modena and Reggio Emilia) for their valuable contribution in the drafting of the present article.

\section{Funding sources}

This research did not receive any specific grant from funding agencies in the public, commercial, or not-for-profit sectors.

\section{References}

Anastassiades, M., Lehotay, S. J., Stajnbaher, D., \& Schenck, F. J. (2003). Fast and easy multiresidue method employing acetonitrile extraction/partitioning and "dispersive solid-phase extraction" for the determination of pesticide residues in produce. Journal of AOAC International, 86, 412-431.

Araujo, P. (2009). Key aspects of analytical method validation and linearity evaluation. Journal of Chromatography B, 877, 2224-2234.

Aresta, A., Cioffi, N., Palmisano, F., \& Zambonin, C. G. (2003). Simultaneous determination of ochratoxin A and cyclopiazonic, mycophenolic, and tenuazonic acids in cornflakes by solid-phase microextraction coupled to high-performance liquid chromatography. Journal of Agricultural and Food Chemistry, 51, 5232-5237.

Asam, S., Konitzer, K., \& Rychlik, M. (2011). Precise determination of the Alternaria mycotoxins alternariol and alternariol monomethyl ether in cereal, fruit and vegetable products using stable isotope dilution assays. Mycotoxin Research, 27, 23-28.

Barkai-Golan, R. (2008). Alternaria mycotoxins. In R. Barkai-Golan, \& P. Nachman (Eds.) Mycotoxins in fruits and vegetables (pp. 185-203). San Diego, CA, USA: Academic Press.

Bottalico, A., \& Logrieco, A. (1992). Alternaria plant diseases in Mediterranean countries and associated mycotoxins. In J. Chełkovski, \& A. Visconti (Eds.). Alternaria biology, plant diseases and metabolites (pp. 209-232). Amsterdam, Netherlands: Elsevier.

Costain, R. M., Fesser, A. C. E., McKenzie, D., Mizuno, M., \& MacNeil, J. D. (2008). Identification of hormone esters in injection site in muscle tissues by LC/MS/MS. Food Additives and Contaminants: Part A, 25, 1520-1529.

De Paola, E. L., Montevecchi, G., Masino, F., Garbini, D., Barbanera, M., \& Antonelli, A. (2017). Determination of acrylamide in dried fruits and edible seeds using QuEChERS extraction and LC separation with MS detection. Food Chemistry, 217, 191-195.

Drusch, S., \& Ragab, W. (2003). Mycotoxins in fruits, fruit juices, and dried fruits. Journal of Food Protection, 66, 1514-1527.

EFSA (European Food Safety Authority), Arcella, D., Eskola, M., \& Gómez Ruiz, J. A. (2016). Scientific report on the dietary exposure assessment to Alternaria toxins in the European population. EFSA Journal, 14, 4654 (32 pp).

EFSA CONTAM Panel (EFSA Panel on Contaminants in the Food Chain) (2011). Scientific opinion on the risks for animal and public health related to the presence of Alternaria toxins in feed and food. EFSA Journal, 9, 2407 (97 pp).

European Commission (2006). Commission Regulation (EC) No 401/2006 of 23 February 2006 laying down the methods of sampling and analysis for the official control of the levels of mycotoxins in foodstuffs. Official Journal of the European Union, L70, 12-34. 
Feinberg, M. (2007). Validation of analytical methods based on accuracy profiles. Journal of Chromatography A, 1158, 174-183.

Hickert, S., Bergmann, M., Ersen, S., Cramer, B., \& Humpf, H. U. (2016). Survey of Alternaria toxin contamination in food from the German market, using a rapid HPLCMS/MS approach. Mycotoxin Research, 32, 7-18.

IUPAC (International Union of Pure and Applied Chemistry, Analytical Chemistry Division) (1978). Nomenclature, symbols, units and their usage in spectrochemical analysis II. Data interpretation. Spectrochimica Acta Part B: Atomic Spectroscopy, 33, 241-245.

Lau, B. P., Scott, P. M., Lewis, D. A., Kanhere, S. R., Cleroux, C., \& Roscoe, V. A. (2003), Liquid chromatography-mass spectrometry and liquid chromatography-tandem mass spectrometry of the Alternaria mycotoxins alternariol and alternariol monomethyl ether in fruit juices and beverages. Journal of Chromatography A, 998, 119-131.

Lohrey, L., Marschik, S., Cramer, B., \& Humpf, H. U. (2012). Large-scale synthesis of isotopically labeled ${ }^{13} \mathrm{C}_{2}$-tenuazonic acid and development of a rapid HPLC-MS/MS method for the analysis of tenuazonic acid in tomato and pepper products. Journal of Agricultural and Food Chemistry, 61, 114-120.

Malmauret, L., Parent-Massin, D., Hardy, J. L., \& Verger, P. (2002). Contaminants in organic and conventional foodstuffs in France. Food Additives \& Contaminants, 19, 524-532.

Mastovska, K., \& Lehotay, S. J. (2006). Rapid sample preparation method for LC-MS/MS or GC-MS analysis of acrylamide in various food matrices. Journal of Agricoltural and Food Chemistry, 54, 7001-7008.

Miller, J. C., \& Miller, J. N. (2010). Statistics and chemometrics for analytical chemistry (6th ed.). Harlow, U.K.: Pearson Education Ltd110-151.

Motta, S. D., \& Valente Soares, L. M. (2001). Survey of Brazilian tomato products for alternariol, alternariol monomethyl ether, tenuazonic acid and cyclopiazonic acid. Food Additives \& Contaminants, 18, 630-634.

Myresiotis, C. K., Testempasis, S., Vryzas, Z., Karaoglanidis, G. S., \& PapadopoulouMourkidou, E. (2015). Determination of mycotoxins in pomegranate fruits and juices using a QuEChERS-based method. Food Chemistry, 182, 81-88.

Noser, J., Schneider, P., Rother, M., \& Schmutz, H. (2011). Determination of six Alternaria toxins with UPLC-MS/MS and their occurrence in tomatoes and tomato products from the Swiss market. Mycotoxin Research, 27, 265-271.

Ostry, V. (2008). Alternaria mycotoxins: an overview of chemical characterization, producers, toxicity, analysis and occurrence in foodstuffs. World Mycotoxin Journal, 1, $175-188$.

Plossl, F., Giera, M., \& Bracher, F. (2006). Multiresidue analytical method using dispersive solid-phase extraction and gas chromatography/ion trap mass spectrometry to determine pharmaceuticals in whole blood. Journal of Chromatography A, 1135, 19-26.
Prelle, A., Spadaro, D., Garibaldi, A., \& Gullino, M. L. (2013). A new method for detection of five alternaria toxins in food matrices based on LC-APCI-MS. Food Chemistry, 140, $161-167$.

Reinhold, L., \& Bartels, I. (2010). LC-MS/MS determination of Alternaria toxins in vegetables and fruit beverages, Agilent Technologies application note \#SI-01322.

Rodriguez-Carrasco, Y., Manes, J., Berrada, H., \& Juan, C. (2016). Development and validation of a LC-ESI-MS/MS method for the determination of Alternaria toxins alternariol, alternariol methyl-ether and tentoxin in tomato and tomato-based products. Toxins, 8, 328.

Rubert, J., Dzuman, Z., Vaclavikova, M., Zachariasova, M., Soler, C., \& Hajslova, J. (2012). Analysis of mycotoxins in barley using ultra high liquid chromatography high resolution mass spectrometry: Comparison of efficiency and efficacy of different extraction procedures. Talanta, 99, 712-719.

Scott, P. M. (2001). Analysis of agricultural commodities and foods for Alternaria mycotoxins. Journal of AOAC International, 84, 1809-1817.

Sobieralski, K., Siwulski, M., \& Sas-Golak, I. (2013). Nutritive and health-promoting value of organic vegetables. Acta Scientiarum Polonorum. Technologia Alimentaria, 12, $113-123$.

Stubbings, G., \& Bigwood, T. (2009). The development and validation of a multiclass liquid chromatography tandem mass spectrometry (LC-MS/MS) procedure for the determination of veterinary drug residues in animal tissue using a QuEChERS (QUick, Easy, CHeap, Effective, Rugged and Safe) approach. Analytica Chimica Acta, 637, 68-78.

Sun, J., Li, W. X., Zhang, Y., Hu, X. X., Wu, L., \& Wang, B. J. (2016). QuEChERS purification combined with ultrahigh-performance liquid chromatography tandem mass spectrometry for simultaneous quantification of 25 mycotoxins in cereals. Toxins, 8 , 375.

Terminiello, L., Patriarca, A., Pose, G., \& Fernandez Pinto, V. (2006). Occurrence of alternariol, alternariol monomethyl ether and tenuazonic acid in Argentinean tomato puree. Mycotoxin Research, 22, 236-240.

Tölgyesi, Á., Stroka, J., Tamosiunas, V., \& Zwickel, T. (2015). Simultaneous analysis of Alternaria toxins and citrinin in tomato: an optimised method using liquid chromatography-tandem mass spectrometry. Food Additives \& Contaminants: Part A, 32, 1512-1522.

Walravens, J., Mikula, H., Rychlik, M., Asam, S., Devos, T., Njumbe Ediage, E., ... De Saeger, S. (2016). Validated UPLC-MS/MS methods to quantitate free and conjugated Alternaria toxins in commercially available tomato products and fruit and vegetable juices in Belgium. Journal of Agricultural and Food Chemistry, 64, 5101-5109. 